\title{
Exploitation of National Fitness Project in Physical Education in Middle School
}

\author{
Yalong Li', Huijian Wang'2, Mintao Deng1 \\ ${ }^{1}$ Department of Physical Education, Baoding University, Baoding, China \\ ${ }^{2}$ Department of Foreign Languages, Baoding University, Baoding, China \\ Email: suibianlong@126.com
}

How to cite this paper: Li, Y. L., Wang, $\mathrm{H}$. J., \& Deng M. T. (2017). Exploitation of National Fitness Project in Physical Education in Middle School. Advances in Physical Education, 7, 409-417.

https://doi.org/10.4236/ape.2017.74034

Received: August 9, 2017

Accepted: November 6, 2017

Published: November 9, 2017

Copyright (c) 2017 by authors and Scientific Research Publishing Inc. This work is licensed under the Creative Commons Attribution International License (CC BY 4.0).

http://creativecommons.org/licenses/by/4.0/

(c) (i) Open Access

\begin{abstract}
This paper describes the significance, constitution and approaches of exploiting national fitness project in physical education in middle school. It states that the exploitation of national fitness project is helpful to achieve the educational goal of "people-oriented", the traditional sports culture can be widely disseminated and effectively inherited; the cultural value of school sports can be enriched. It elaborates the national fitness project mainly consists of projects of entertainment, competition and those reflecting the festival. This paper discusses the approaches of exploiting national fitness project, such as changing the concept of education and establishing a scientific concept of sports resources, further strengthening the sorting, excavation and research of national traditional fitness project, meeting young students' physical and mental characteristics of in the choice of content, and highlighting the national characteristics and geographical characteristics of national fitness projects. It aims to integrate the national fitness project into physical education, enrich the resources of middle school PE curriculum and promote the comprehensive development of middle school students.
\end{abstract}

\section{Keywords}

National Fitness Project, Exploitation, Physical Education, Middle School

\section{Introduction}

In the historical development of the Chinese nation for thousands of years, the people of all ethnic groups have created a large number of excellent national fitness projects such as dragon dance, lion dance, rubber band skipping, shuttlecock, fireworks, pearl ball, wooden ball, cuqiu, shuttlecock and so on. These projects are rich in content and diverse in forms, with effect of fitness and dis- 
ease prevention as well as a strong interest, entertainment and flexibility, which are treasures of the traditional fitness and an important part of traditional Chinese culture.

National traditional sports play an important role in the national fitness and get inherited and developed, which has become the concern of many scholars and research. With the universal development of the national fitness campaign, national traditional sports ushered in an unprecedented opportunity, which also makes excavation and finishing work more realistic (Zeng, 2004).

Traditional sports have distinctive historical, ethnic and regional characteristics. The excavation and finishing of the traditional sports is to cite and popularize them in the national fitness campaign, so as to enrich the content of traditional national sports projects in China ( $\mathrm{Ma}, 2011)$.

The aim of promoting sustainable development of national fitness is not only to improve the nation's physical constitution, but also to inherit national sports culture. National traditional sports, such as tai chi, qigong, shuttlecock, kite, rope skipping, etc., greatly promote the breadth and depth of sustainable development of national fitness campaign, which is a practical choice of the development of national fitness (Qiu, 2015).

Some scholars have summarized the connotation, classification system and cultural characteristics of the traditional sports of art fitness. It is divided into six types: dancing-playing type, dancing type, yangko type, dressing type, drum type and props type. It has cultural characteristics of regional folklore, cultural and physical integration, health and entertainment and competitive experience (Zhang \& Li, 2015).

In general, most scholars have studied the characteristics of the national traditional sports and recognized its status and role in national fitness campaign from the theoretical point of view. But, at present, few scholars have studied the introduction of national traditional sports into school physical education, and there are some deficiencies in this field. Therefore, it is of practical significance to carry out the exploitation of national fitness project in physical education in middle school.

In the new round of basic education curriculum reform, it is necessary to introduce and exploit these national fitness projects, and put these rich and colorful national fitness project into the physical education, which is an important measure to implement the spirit of curriculum reform, to enrich the secondary school physical education curriculum resources, and to cultivate a comprehensive development of the people important move. Also, it is a method to enhance students' local cultural quality and a sustainable path to inherit traditional national sports under the impact of modern culture.

\section{The Significance of the Exploitation of National Fitness Projects for Physical Education in Middle School}

\subsection{The Constitution of the National Fitness Projects}

Chinese traditional national fitness projects are created and developed by ethnic 
groups in different geographical environment under different historical and cultural background. Therefore, their forms of expression can be described as rich and varied. According to the content and form, the national fitness projects can be divided into three categories:

1) Giving priority to entertainment. Such projects regard leisure and recreation, fitness and entertainment as the main purpose. Although there are certain rules, they are not strict. They have a wide range of mass because they are not subject to age, occupation, geographical, economic conditions or customs and habits, such as sandbags, eagle and chickens which are welcome in many places.

2) Giving priority to competition. This kind of projects has both the composition of the game entertainment, and the content of the competition. It is a kind of physical activity stressing on strength and skill, such as dragon boat race in Hunan, wrestling of Mongolian, and climbing pole of Jingpo and so on.

3) Reflecting the custom of festivals. This kind of projects plays an important role in inheriting traditional culture with a unique cultural expression, such as lion dance, dragon dance, land boat, stilts, yangko dance and drums, which are prevalent in North China (Li, 2000).

\subsection{The Significance of the Exploitation of National Fitness Projects for Physical Education in Middle School}

First of all, the exploitation of national fitness projects will help to achieve the goals of "people-oriented" education.

The concept of "People-oriented" recognizes that each student is learning the subject. At the same time, it not only emphasizes the students' differences in personality, but also stresses that all students can be fully developed. "Guide for National Basic Education Curriculum Reform" states: "Students are learning master. The development of students is the starting point and destination of teaching activities. Learning should be the basic way of the development of students' intelligence and forming healthy personality." (Ministry of Education, 2006) A prominent feature of national fitness projects is that there are more activities with wide adaptability and entertainment. Everyone can participate in such fitness activities, regardless of people of high and low level. If introduced into physical education in secondary school, these projects will correct or reduce the drawbacks in modern competitive sports which are caused by the gap between great concern on skilled participants and neglect to the poor ones, which is conducive to the implementation of education for all students.

Second, the exploitation of national fitness projects will help to inherit the traditional national sports culture.

The national fitness project is an important part of the Chinese traditional culture. It is the experience of the working people struggling with the disease in the process of surviving and living for thousands of years, which embodies the creation and wisdom of all ethnic groups. Since the foundation of new China, a lot of work has been done in inheriting traditional national sports culture (such as the holding of National Minority Traditional Sports Games every four years). 
But at the same time, with the transformation of society and the globalization of sports development, people pay less attention to the traditional sports culture, resulting in a desalination trend in the unique recreational function, fitness function, competitive function and connotation of rich national culture (Li, 2000). Therefore, the exploitation of national fitness projects and advocating of traditional national sports culture are the common tasks of educators and sports workers of all levels.

Third, from the perspective of school physical education, students, as the main body of school sports, are undoubtedly important successors of sports culture. For this reason, if combined with the local and the actual reality to actively organize, tap and exploit national fitness projects, the secondary school physical education will provide students with more opportunities to access to a large number of folk sports (such as Dragon Dance and Lion Dance during Lantern Festival; Dragon Boat competition during Dragon Boat Festival). So students will get sensible knowledge and direct experience in this kind of sports activities and which is completely different from that in classroom. Through this way, the national traditional sports culture will be widely disseminated and effectively inherited.

Finally, the development of national fitness programs will help to enrich the cultural value of school sports.

School sports culture is an important manifestation of school sports ideology. Healthy and positive school sports culture is conducive to students to form the correct sports values and establish correct sports awareness, which is helpful for students to better accept, comprehend, spread the core content of Olympic thought-peace and friendship; fair competition; courage to participate and proactive; harmonious development, comprehensive progress. Chinese traditional national fitness project, with a long history and self-contained system, has a rich variety of internal forms and unique cultural connotation. After the introduction into secondary school physical education, it can not only meet the youth visual, auditory, tactile and other aesthetic need, but also play a role in increasing knowledge, broadening horizon, spreading culture, exercising will and cultivating temperament, which is great helpful to young students' the physical and mental health, helps to establish their sense of lifelong physical exercise, greatly enriching the cultural value of school sports system.

\section{Problems in the Exploitation of National Fitness Project in Physical Education in Middle School}

\subsection{Inadequate Attention Paid by School Authority}

First of all, school authorities are not aware of the importance of inheritance and development of national traditional fitness project. Secondly, there is lack of scientific planning for the exploitation of national fitness project in school, and correspondingly there is lack of special funds for school-based curriculum development which restricts the development of the national traditional sports curriculum. 


\subsection{Lack of National Fitness Project in Sports Curriculum}

In general, the teaching material of sport curriculum in middle school is relatively simple. It is Sports and Health that is used in all of the middle schools. The content involves track and field, football, basketball and volleyball, with no reference to national fitness project. Even if there are some teaching items about localized national sports, they are taught by some teachers or inheritors with personal skills. There is not unified teaching material and standard, which makes the teaching a bit blind.

\subsection{Lack of Teachers}

Teachers are different from each other in profession, ability and qualification. There are few teachers major in the traditional sports projects. Some teachers teach traditional national sports as amateurs, but their skill level cannot meet the needs of students. Some inheritors of national traditional sports are not qualified for teaching. These make it difficult to carry out national traditional fitness project in middle school.

\subsection{Lack of Site and Facilities}

There is need for corresponding sites and supporting facilities to carry out national traditional sports project in physical education in middle school. For example, the introduction of these projects such as land boat and dragon dance both need adequate facilities and site which will not affect the daily teaching. The missing of each side will affect the introduction and development of the project.

\section{Approaches to Exploit National Fitness Projects in PE in Middle School}

All national fitness projects have the common features of entertaining, group and flexibility. So they are very suitable for young students to participate in, just like an inexhaustible treasure to enrich PE curriculum in middle school. The exploitation of national fitness projects should be carried out in accordance with principles of scientific development and effective use and preceded from the following aspects.

\subsection{Changing the Concept of Education and Establishing a Scientific Concept of Sports Resources}

Thought is the leader of action. In China, with the transformation of examination-oriented education to quality education and the implementation of new curriculum standards, the exploitation of national fitness project as school-based curriculum resources has been paid more and more attention. Also the theoretical research on this field goes increasingly deeper. But in the specific practice, there is still a long way to go to ensure scientific exploitation, rational use of the national fitness project and extensive promotion. Notice of the State Council on the issuance of the National Fitness Program (2011-2015) states: "Inherit and 
develop national and folk traditional sports. Lay stress on the work of excavation, dissemination and propaganda of national and folk traditional fitness project, carrying forward the national traditional sports culture. Put the excellent folk traditional sports projects into the directory of 'intangible cultural heritage', to be inherited and protected. Universally carry out national traditional sports education activities, held national folk traditional sports exhibition and competition activities, promote the national and regional exchanges, and expand the international influence of national folk traditional sports." (National Sports Association, 2011)

Therefore, the primary task of exploitation of national fitness sports project is to transform the concept of authorities and majority of educators of physical education to establish a scientific concept of sports resources and to follow "health first", "lifelong sports" as the guiding ideology of exploitation of national fitness project under the premise of obeying educational rules.

\subsection{Increasing Investment, Improving the Sites and Facilities and Building Teacher System of National Fitness Project}

The relevant education authorities and schools need to increase the investment in sports equipment and sports sites to improve and enrich the national sports fitness projects, so that teachers and students have a greater space of choice in teaching and learning. In addition, it is necessary to build a teacher system of national fitness project. The Ministry of Education, the provincial and municipal education bureaus can entrust the major physical education institutions to cultivate talents for the national fitness project to ensure a certain number and high quality of skilled people. Training courses can be organized for non-professional teachers to attend systematic training. And the school should also encourage in-service teachers to take part in further study in professional schools. In the study, they should not only pay attention to skills training, but also to the acquirement of scientific theoretical knowledge, so as to meet the need of carrying out the national fitness project in middle school.

\subsection{Reasonable Exploitation of Traditional Fitness Project}

\subsubsection{Further Strengthening the Sorting, Excavation and Research of National Traditional Fitness Project}

At present, the urgent task of scientific and rational exploitation of national fitness projects is to strengthen the sorting, excavation and research of national traditional fitness project. The national fitness projects, rich in form, charming in culture, mostly exist in the folk traditional activities. They have both functions of entertainment and fitness. They have a broad mass and popular. In order to introduce the national fitness project into physical education in middle school to be resources of sports curriculum, the first thing to do is to understand the reality, visit the masses, and make investigations on local national fitness project to find its ins and outs, the project's cultural connotation, skill requirements and so on. And then organize those materials into a book or image data which facilitate 
classroom teaching. In this regard, Beijing has provided us with a successful case. Under the guidance of the Municipal Sports Bureau, the Beijing National Traditional Sports Association, with more than 10 years efforts, has excavated more than 100 national and folk games, sorted and stereotyped of more than 30 national traditional sports projects. The excavated national traditional sports have been designated as the official events in national minority traditional sports games, such as pearl ball, wooden ball, cuqiu. Five projects, including rubber band skipping, hopscotch, skipping, kicking shuttlecock, rolling a hoop were cited in Chinese Sports Fitness Methods (Volume 1) which was edited and published by 10 national ministries and was popularized in the whole country $(\mathrm{Wu}$, 1996).

\subsubsection{Meeting Young Students' Physical and Mental Characteristics of in the Choice of Content}

The national fitness projects exploited and used in physical education in middle school have to meet the young students' physical and mental characteristics and be chosen based on the student's gender, age, interest and skills. The implement should be targeted. To be specific, the projects should be chosen on the basis of students' ability to achieve, willing to take part in and acceptance. The exploitation should focus on the projects of strong interest, entertainment and high security, because only laughing and interesting projects can arouse students' interest in learning. In addition, high security is conducive to teaching organizations and extracurricular activities, avoiding injury accidents as possible.

In the selection of the content of national fitness sports exploitation, we should pay attention to its complete agreement with current educational goals and curriculum objectives, to the absolute agreement with the idea of "people-oriented", which should highlight concept of "health first". We should not take it for granted that it is exploitation and implementation of national fitness sports to simply compile several sets of action. To this end, when exploiting national fitness sports projects, we both need to strengthen the teachers' understanding of physical education and establish their scientific concept of sports resources. We should integrate the national fitness sports into classroom teaching according to the reality step by step. Meanwhile, authorities should be required to raise their awareness, attach importance to the exploitation of national fitness program curriculum resources and make it included into the school teaching plan and arranged reasonably. Only by this way can the exploitation achieve a satisfying effect.

Some projects are easy to arouse students' interest and relatively safe to be introduced into the PE class, such as pulling sticks, playing marbles, throwing sandbags, rope skipping, kicking shuttlecock, riding cock-horse, dragon dance, go land-boating, playing Kongzhu (diabolo) and so on, all of which will receive the expected teaching effect. In addition, Chinese traditional festivals can help to create a real environment and a variety of learning activities for students. Taking Lantern Festival for example, there is a common custom of dragon dance in a lot 
of places on that day. It provides a good opportunity to organize students to make lanterns and perform the dragon lantern. Also the folk artists and sports groups can be invited to guide students to make and perform dragon lantern, to tell about the origin of the dragon lantern, which provides students with practical environment and opportunity to learn Chinese traditional culture.

\subsubsection{Highlighting the National Characteristics and Geographical Characteristics of National Fitness Projects}

The reason why National fitness project has been able to endure for such a long time is that it has national features, it is derived from the real life of all ethnic groups and cultural traditions, and embodies the cultural connotations of various nationalities. Therefore, the exploitation of national fitness projects used in PE in middle school should highlight its inherent national characteristics and the national traditional culture.

At the same time, the exploitation of national fitness projects in physical education in middle school should also highlight its geographical characteristics, because the folklore has regional characteristics. Different regions have different national folk sports. So we should exploit selectively and effectively according to local conditions, taking local and school reality into consideration, it is benefit for highlighting the characteristics of regional national fitness projects and carrying forward the local characteristics of traditional culture. Taking Kongzhu, a traditional sports project with a very strong regional cultural characteristic, for example, it is an ancient sport as well as an important part of the ancient temple. Chuang-tzu had ever described the feat of playing Kongzhu (Ma, 2008). In 2006, with the approval of the State Council, Kongzhu was included in the first batch of State-level non-material cultural heritage list. In traditional Chinese society, children playing Kongzhu has always been considered as a kind of appearance of peace and prosperity, and thus often became the object of poet. Today, we can put this sports activity with long history and extensive mass into physical education curriculum system in middle school. We also can regularly or irregularly organize individual or group competition, so that the national sports will get further developed and play an increasingly important role in the heritage of sports culture in the new era (Qin, 2010).

\section{Conclusion}

National sports fitness projects, with strong interest, entertainment and flexibility, are treasures of the traditional fitness and an important part of traditional Chinese culture. However, with the rapid infiltration of modern culture, the cultural atmosphere of national traditional sports has been weakened, and some precious national traditional sports have been neglected and faced with the destruction and loss. At present, the sports class of all kinds of schools in our country has become the transmission area of the western sports culture such as football, basketball, and volleyball, which shows the absence of protection of traditional sports. It is a feasible way for the traditional sports to be introduced into 
sports classroom to get out of the predicament.

Therefore, the exploitation of national fitness project, which aims to integrate national fitness project into physical education in middle school, will contribute to enrich the resources of PE curriculum and the educational goal of the "people-oriented", to promote the comprehensive development of middle school students. It can also enrich the cultural value of school sports and get the traditional national sports culture widely disseminated and effectively inherited.

\section{Acknowledgements}

The paper is under the project of Modern Leisure Sports and Scientific Training (Project No. 17K55701D) which is sponsored by Science and Technology Department of Hebei Province.

\section{References}

Li, H. J. (2000). Introduction to Chinese National Sports. Beijing: China Book Publishing House.

Ma, Y. F. (2011). On the Popularization of Minority Traditional Sports in National Fitness, Journal of Northwest University for Nationalities (Natural Science), 32, 75-78.

Ma, Z. Z. (2008). Chuang-tzu Education. Lanzhou: Gansu Culture Publishing House.

Mao, D., \& Hong, X..B. (2010). Analysis of the School Sports and Heritage of Sports culture. Journal of Anhui Agricultural University (Social Science Edition), 2, 131-133.

Ministry of Education (2006). Guide for National Basic Education Curriculum Reform (Trial).

National Sports Association (2011). Notice of the State Council on the issuance of the National Fitness Program (2011-2015). Beijing: People's Sports Publishing House of China.

Qin, H. S. (2010). Study on the Development of Kongzhu Movement. Journal of Sports Culture, 12, 100-104+108.

Qiu, S. H. (2015). Inheritance and Application of Ethnic Traditional Sports in Sustainable Development of National Fitness, Bulletin of Sport Science and Technology, 23, 16+25.

Wu, S. Z. (1996). Chinese Sports Fitness Methods (Volume 1). Tianjin: Tianjin Science and Technology Publishing House.

Zeng, S. H. (2004). A Research on Traditional National Sports. Journal of Shaoxing University (Natural Science), 3, 114-117.

Zhang, G. Q., \& Li, P. (2015). On Item Classification and Cultural Characteristics of Traditional Ethnic Sports of Art and Fitness Class. Journal of Guangzhou Sport University, 5, 66-69. 